\title{
SEHAT DALAM AYURWEDA
}

\author{
Ida Bagus Wiryanatha \\ Program Studi Kesehatan Ayurweda, Fakultas Kesehatan \\ Universitas Hindu Indonesia \\ E-mail :wirya61@gmail.com
}

\begin{abstract}
Abstrak
Umat Hindu memiliki kitab suci Weda yang sangat terkenal.Kitab suci ini terbagi dalam dua golongan besar yakni kitab Sruti dan Smerti.Keduanya masing-masing dibagi-bagi lagi menurut kumpulan isinya.Kitab Ayurweda yang merupakan upaweda dari Kitab Rg Weda mengandung banyak tentang sistem pengobatan yang sangat mendasar.Sistem pengobatan ini dibagi lagi menjadi 8 (delapan) sub sistem yang dikenal dengan Astangga Ayurweda.Konsep sehat secara ayurweda memberikan tuntunan untuk mencapai sehat jasmani maupun rohani yang dikenal dengan sehat secara holistik.Konsep sehat dalam ayurweda identik dengan konsep sehat menurut WHO (World Health Organisation). Hal pokok yang membuat kedua konsep ini sama ialah bahwa sehat itu tidak hanya melibatkan komponen fisik namun juga sosial dan spiritual. Untuk memelihara hidup agar tetap sehat, perlu diketahui konsep sehat dalam ayurweda serta upaya pemeliharaannya dengan konsep Tri Upasthamba :Ahara (tentang diet), Nidra (tentang pola tidur) dan Brahmacharya (pengendalian energi seksual). Orang akan senantiasa sehat (swasthya)bilamanamemahami konsep sehat dan dapat mengatur pola makanan, pola istirahat dan pengendalian energi seksual yang benar. Kesehatan adalah modal utama mencapai cita-cita hidup oleh karenanyapengetahuan tentang konsep sehat dalam ayurweda dan upaya memelihara kesehatan perlu senantiasa diketahui untukkemudian dipraktekkan dalam upaya menghidari diri dari gangguan penyakit.
\end{abstract}

Kata kunci : Ayurweda, konsep sehat,Tri Upasthamba

\section{Abstract}

Hindus have a very famous Vedic scripture. This holy book is divided into two major groups namely Sruti and Smerti. Both of them are divided again according to the collection of contents. The book of Ayurvedic which is the upaweda of the Reda Weda Book contains a lot of very basic medical systems. This treatment system is further divided into 8 (eight) sub-systems known as Astangga Ayurvedic. The concept of healthy in ayurweda provides guidance to achieve physical and spiritual health which is known as a holistic health. The concept of health in ayurweda is identical to the healthy concept according to the WHO (World Health Organization). The main thing that makes these two concepts the same is that health does not only involve the physical component but also social and spiritual. To maintain life to stay healthy, it is necessary to know the healthy concept of relaxation and maintenance efforts with the concept of Tri Upasthamba: Ahara (about diet), Nidra (about sleep patterns) and Brahmacharya (sexual energy control). People will always be healthy when they understand healthy concepts and can regulate food patterns, patterns of rest and control of sexual energy properly. Health is the main capital to achieve the ideals of life, therefore the knowledge of healthy concepts in a sustainable manner and efforts to maintain health need to always be known to be practiced in an effort to avoid the disease.

Keywords: Ayurvedic, healthy concept, Tri Upasthamba 


\section{Pendahuluan}

Kehidupan masyarakat jaman dahulu khususnya di India, pengobatan adalah kebiasaan hidup yang senantiasa dilaksanakan bagaikan melaksanakan kehidupan lainnya yang tak kalah pentingnya. Seperti diketahui, kitab suci weda terbagi menjadi beberapa bagian dan tertulis menggunakan aksara dewa negari dan bahasa sanskerta merupakan bahasa yang sudah mati, tidak dipakai lagi dalam berkomunikasi sehari-hari dalam pergaulan. Sedangkan kitab ayurweda yang diyakini para sarjana merupakan kitab upaweda dari AtharvaWeda. Istilah ayurweda oleh masyarakat sering dikelirukan pemahamannya dengan kitab YajurWeda yang merupakan bagian dari kitab weda sruti mantra.Dari uraian pada beberapa kitab, tampak jelas posisi keberadaan kitab Yajur weda sangat berbeda dengan keberadaan kitab ayurweda. Isi kitab Yajurweda pada intinya adalah membahas banyak tentang mekanisme upacara yadnya diantaranya adalah Dewa Yadnya, ResiYadnya, PitraYadnya, ManusaYadnya serta ButhaYadnya. Sedangkan isi dari kitab ayurweda kebanyakan membahas tentang pengobatan penyakit, tehnik mendiagnose, pengobatan dengan herbal dan lain sebagainya yang membuat hidup ini sehat dan berumur panjang. Banyak sarjana yang telah mengakui dan meyakini bahwa ayurweda adalah Ilmu Kedokteran yang dimiliki oleh agama Hindu karena lahirnya pada jaman kelahiran kitab - kitab weda tersebut di India. Filosofi dari pengobatan modern saat ini banyak mengacu pada ayurweda. Sebagai contoh, sering seorang dokter modern memberikan nasihat agar pasiennya memelihara kesehatannya mulai dari mengatur makanan, mengatur istirahat dan mengatur aktivitas jangan membebani fisik. Hal ini jelas termuat dalam kitab ayurweda khususnya pada perkembangan ayurweda tertulis dalam kitab swasthya writta.Sekali lagi supaya lebih jelas diterangkan bahwa isi kitab ayurweda lebih diyakini berasal dari kitab AtharvaWeda karena ada korelasi dan keidentikan dari segi isi dan kumpulan slokanya kebanyakan sama tentang tatacara pengobatan.

Sebagai umat Hindu sepatutnya sangat bersyukur kehadapan Ida SanHyang Widhi Wasa/Tuhan Yang Maha Kuasa, karena sejak jaman dahulu dituntun bisa hidup sehat dan berumur panjang. Tuntunan Beliau termuat di dalam kitab ayurweda yang merupakan bagian dari upaweda.Mempelajari keberadaan Ayurweda dalam kitab weda merupakan kewajiban setiap umat Hindu yang mencintai hidup sehat berumur panjang. Artinya selama hidup ini, manusia tetap berada dalam tubuh yang sehat dan jiwa yang sehat. Dalam ayurweda dikenal dengan swasthya yaitu sehat secara jasmani dan bahagia serta diterima dalam kehidupan masyarakat, tidak terkucilkan terutama berkecukupan dari segi ekonomi. Itu dalam kehidupan fisik. Selanjutnya sehat secara psikis juga merupakan kewajiban. Diantaranya adalah sehat dalam mengatur keinginan panca indera, hidup mengatasi Tri Guna (satwam; rajas; tamas) yang semuanya bertujuan supaya mengalami ketenangan pikiran untuk menjadikan jiwa/roh/atman itu bahagia. Ayurweda terdiri dari dua suku kata ayurlayulayus yang artinya sehat berumur panjang dan dari kata veda yang artinya pengetahuan. Sistem kesehatan ini telah dipraktekkan lebih dari 2000 tahun yang lalu. Termasuk di dalamnya adalah terapi, filosofi gaya hidup, kehat dan bahagia (Mahadevan: 1). Diyakii pengetahuan untuk bisa hidup sehat dan berumur panjang pada awalnya terdapat dalam kitab ayurweda. Untuk mengetahui lebih jauhyang tersebut dalam ayurweda sewajarnya setiap orang perlu mengetahui keberadaan kitab ayurweda terlebih dahulu sebelum mengungkap permasalahan-pemasalahan lain menyangkut kesehatan secara holistik, menyeluruh.

\section{Pembahasan}

Istilah ayurweda merupakan kata yang termuat dalam bahasa Sanskerta berasal dari dua suku kata : ayur dan weda. Untuk memahami kitab ayurweda, sebelumnya harus diketahui pembagian kitab weda itu terlebih dahulu agar dapat dipetakan secara rinci sehingga dapat lebih difahami.Weda adalah merupakan kitab sucinya Agama Hindu, agama tertua di dunia dari hasil penelitian sejarah, oleh karenanya, kitab weda adalah kitab suci paling tua di dunia.Kitab weda dibagi menjadi 2 (dua) kelompok besar yaitu kitab WedaSruti dan Kitab WedaSmerti. Kitab WedaSruti dibagi atas tiga kelompok lagi yaitu : (1) kitab WedaSrutiMantra; (2) KitabBrahmana; dan (3) KitabUpanisad (Nala 2001:14). Ketiganya mempunyai kualitas dan kedudukan yang sama sebagai kitab suci. Kitab wedapertama kali ditulis langsung oleh Maharshi berdasarkan wahyu yang didengaroleh beliaudalam semadinya tanpa ditambah lagi dengan penafsiranpenafsiran. Sementara kitab weda SrutiMantra yang merupakan bagian dari kitab WedaSruti, 
terbagi lagi menjadi 4 (empat) himpunan besar (Samhita) sehingga sering disebut CaturWedaSrutiSamhita.Keempat Samhita inilah (1) RgWeda; (2) SamaWeda; (3) YajurWeda dan (4) AtharvaWeda yang dikenal di masyarakat secara umum baik oleh kalangan Hindu maupun oleh umat lainsebagai kitab Catur Weda. Sementara itu Kitab WedaSmerti terbagi atas 2(dua) kelompok besar yakni WedaSmertiWedangga dan WedaSmertiUpaweda. Kelompok kitab Suci Wedangga ini terdiri dari 6 (enam) kitab sehingga dikenal dengan istilah WedaSmertiSadWedangga karena terdiri dari enam kelompok besar $(\mathrm{sad}=$ enam). Yang termasuk kitab WedaSmertiSadWedangga adalah : (1) Siksa yaitu ilmu phonetika atau ilmu bunyi weda; (2) Wyakarana yaitu ilmu tatabahasa weda; (3) Nirukta yaitu ilmu tentang etimologi atau ilmu asal-usul kata dalam weda; (4) Jyotisa yaitu ilmu astronomi astrologi yang belakangan dikenal sebagai ilmu matematika; (5) Chanda yaitu ilmu tentang irama, baik irama dalam melantunkan seloka weda maupun dalam melantunkan wirama kakawin dan (6) Kalpa yaitu ilmu tentang pelaksanaan ritual atau upacara yadnya. Di Bali oleh umat Hindu dikenal sebagai panca yadnya yang artinya semua ritual digolongkan menjadi lima besar (Dewa, Resi, pitra, manusa dan buta yadnya). Sedangkan Kitab Suci WedaSmertiUpaveda terdiri dari beberapa kelompok yakni :Itihasa; Purana; Arthasastra, Ayurweda, Gandharvaweda, Agama/Tantra. Nah jelaslah sekarang bahwa kitab ayurweda dimaksukkan ke dalam kelompok upaweda namun kandungan muatan di dalam kitab ayurweda lebih banyak memuat isi yang bersumber dari kitab atarva weda.

\subsection{Pokok-pokok ajaran dalam Ayurweda}

Adapula sarjana yang mengatakan bahwaAyurweda adalah bagian upaweda dari KitabRgWeda, namun keyakinan itu akhirnya berubah karena para sarjana lebih meyakini ayurweda merupakan bagian upaweda dari kitab AtharvaWeda (Dash, 2008: 24).Pokok-pokok ajarannya Ayurweda sendiri yang merupakan kitab kedokteran Hindu mengandung 8 (delapan) ajaran pokok yang semuanya mengandung ilmu pengobatan tersendiri berbeda-beda dengan yang lainnya namun semuanya ini tidak sama persis dengan ilmu kedokteran modern. Dalam dunia kedokteran modern ke delapan bagian pokok kitab ayurweda ini mirip dengan pembagian sistem pengobatan kedokteran.Pembagian bidang terutama yang khusus berisi tentang penyakit dalam, penyakit bedah dan yang lainnya mendapat perhatian khusus.Lebih dijelaskan ke delapan ajaran pokok yang ada dalam kitab ayurweda yaitu : (1) Kaya Chikitsa (identik dengan Ilmu Penyakit Dalam / Internist); (2) Shalakya Tantra (identik dengan Ilmu Penyakit THT) namun dalam Shalakya Tantra ini termasuk juga ilmu penyakit gigi dan mulut. Inilah yang salah satu yang membedakan pembagian pokok ajaran ayurweda tidak sama dengan pembagian ajaran menurut kedokteran modern; (3) Vishagara-vairodha Tantra (identik dengan ilmu Toxicology yaitu ilmu tentang keracunan tubuh manusia), di dalamnya diuraikan pula tentang binatang beracun yang sering menyakiti manusia seperti racun ular, gigitan serangga, efek neorologi dari racun dan tehnik cara menawar racun apabila menginfeksi manusia seperti akibat rabies gigitan anjing gila; (4) Kaumara Bhritya (identik dengan Ilmu Kesehatan Anak) namun dalam pembahasan kaumara bhritya juga dibahas masalah geriatrik. Mungkin karena karakter orang tua sudah mirip lagi dengan karakter anak-anak; (5) Shalya Tantra (identik dengan Ilmu Pembedahan); (6) Bhuta Widyadisini (Identik dengan Ilmu Psikiatri dan Psikologi); (7) Vajikarana (Ilmu tentang pengobayan lemah syahwat pada laki-laki); (8) Rasayana yaitu Ilmu tentang awet muda yang sekarang ini banyak diminati karena di dalamnya terdapat pembahasan tentang anti aging yatu menunda proses penuaan dini.

\subsection{Maharshi yang dihormati}

Ada dua orang Maharshi yang sangat dihormati dalam kitab Ayurweda yaitu MaharshiCaraka dan MaharshiSusrutha.Kedua Maharshi ini menganut aliran yang berbeda dalam melaksanakan pengobatan ayurweda.MaharshiCaraka lebih menekankan kepada pengobatan dengan obat-obatan tanpa melakukan tindakan operasi, namun MaharshiSusrutha melakukan pengobatan lebih menekankan kepada tindakan operasi untuk penyakit-penyakit yang memang memerlukan tindakan.Kemungkinan dari kedua aliran Maharshi inilah kemudian berkembang dalam metode kedokteran modern menjadi pengobatan konservatif (dengan memberikan obat-obatan) dan pengobatan operative dengan melakukan tindakan pembedahan.Masing-masing Maharshi ini membentuk perguruan, sehingga dalam 
perkembangannya masing-masing mempunai pengikut-pengikutnya sendiri.MaharshiCaraka misalnya diikuti oleh MaharshiBaradwaja dan MaharshiAtreaPunarvasu.Kedua Maharshi ini kemudian diikuti oleh MaharshiAgniwesa, MaharshiBhela, Jatukarna, Parasara, Harita dan Maharshi Ksharpani.Sedangkan Maharshi Susruta menerima ajaran dari Dewa Danwantari selanutnya diikuti oleh murid-muridnya seperti MaharshiAurabhara, Waitarana, Paushkalawat, Karawirya dan MaharshiGopurarakshita (Sharma 2012).

Dari kumpulan Maharshi yang belajar melalui perguruan MaharshiCaraka dan MaharshiSusruta inilah lahir berbagai kitab Ayurweda seperti yang diwariskan sekarang ini. Kitab Ayurweda yang demikian banyaknya dapat dikelompokkan menjadi dua golongan besar yaitu (A) Kitab Ayurweda Mayor ada tiga jumlahnya yaitu : (1) KitabCarakaSamhita (ditulis oleh Maharshi Caraka); (2) KitabSusruthaSamhita (ditulis oleh Maharshi Susrutha); dan (3) KitabAstanggaSanggraha atau AstanggaHrdaya(ditulis oleh MaharshiBhagavata. Sedangkan (B) disebut Kitab Ayurweda Minor juga ada 3 jumlahnya terdiri dari : (1) KitabMadhavaNidana (ditulis oleh MaharshiMadhavakara); KitabSharangadharaSamhito (ditulis
MaharshiSharangadhara); KitabBhawaprakasa dan MaharshiBhawamishra). Masing-masing kitab ini mempunyai kekhususan isi daripadanya misalnya (Sharma 2012)

> KitabCarakaSamhita memiliki kekhususan tentang sistem pengobatan ayurweda

$>$ SusruthaSamhita tentang denah anatomi tubuh manusia

$>$ MadhawaNidana tentang tehnik Diagnostik Ayurweda

$>$ AstanggaHrdaya tentang konsep dasar apa itu Ayurweda

Jadi bila ingin mendalami tentang tehnik diagnostik penyakit menurut ayurweda sebaiknya dipelajari kitab MahavaNidana, sedangkan bila ingin mengetahui nama-nama dan denah ogan tubuh manusia secara menyeluruh, sebaiknya dipelajari kitab SusruthaSamhita.

Namun demikian bukan berarti masalah anatomi tubuh manusia tidak terdapat dalam Kitab CarakaSamhita.Hal ini hanya memberitahukan bahwa ada kelebihan dari masing-masing kitab tersebut.

Contoh gambar kulit buku dari Kitab SusruthaSamhita dan CarakaSamhita adalah seperti tampak pada gambar di bawah ini.

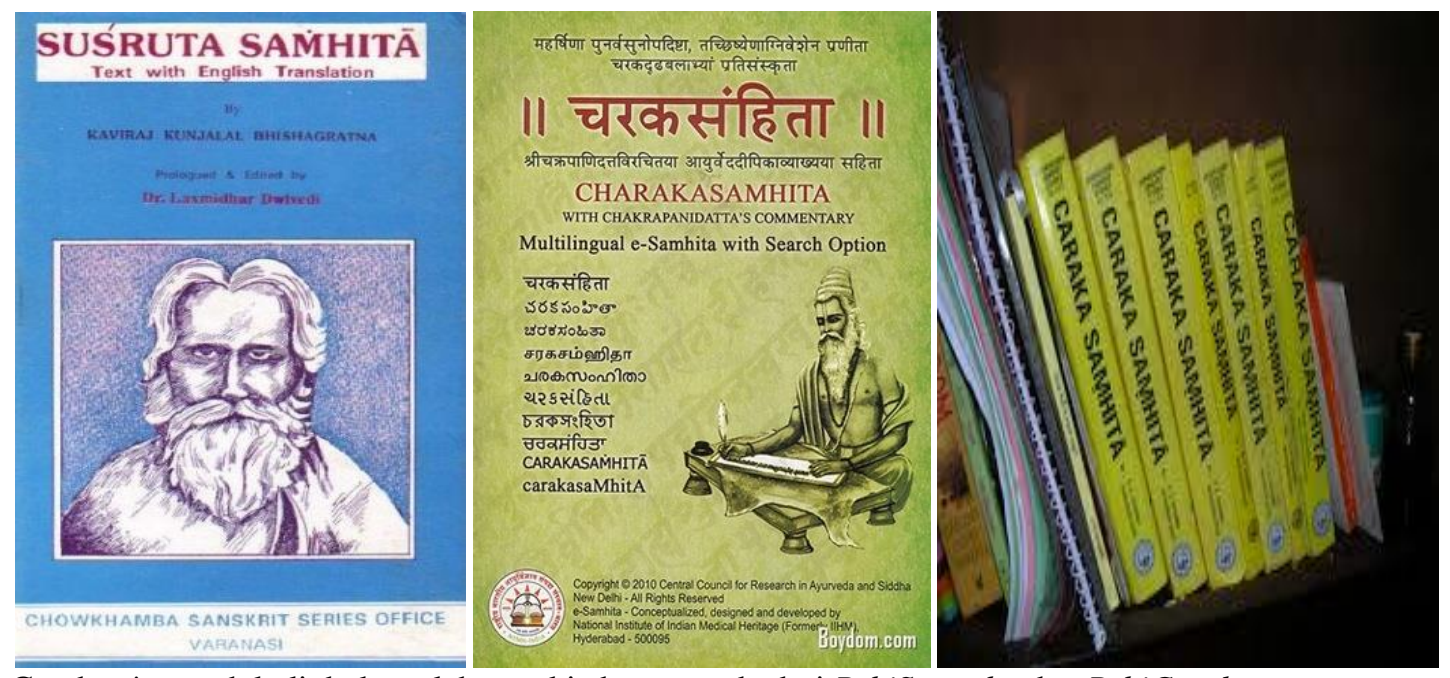

Gambar !.contoh kulit buku salah satu kitab ayurweda dari RshiSusrutha dan RshiCaraka

\subsection{Konsep Sehat Menurut Ayurweda}

Untuk memahami pengertian sehat dalam ayurweda secara umum, sebelumnya harusdipahamiterlebih dahulu beberapa konsep sehat ayurweda yang termuat dalam kitab Susrutha dan kitab CarakaSamhita. Konsep-konsep tersebut antara lain : 
2.3.1 "Sama dosha sama agnischa sama dhatu mala kriya; Prasanam atmendriya manah swasthyaatya ityavidhyate" yang artinya adalah bahwa untuk mencapai sehat maka di dalam tubuh harus terjadi keseimbangan dosha, agni, dhatu dan bekerjanya sistem ekskresi (mala) dengan baik disertai perasaan bahagia yang dialami oleh atman, indria dan manah. Jadi untuk memahami ini semua, kita harus memahami satu demi satu yang disebut dosha, agni, dhatu, mala, atma, indera, dan manah. Jika semua itu dalam kondisi equilibrium (seimbang) serta menimbulkan rasa bahagia dalam atman, indera dan pikiran (manah) barulah seorang dapat dikatakan sehat (swasthya).

2.3.2 "Dirghajiwitam Sukayu \&Hitayu'(Sharma, 2012) . Untuk mengertikan konsep ini, terlebih dahulu kita harus memahami yang disebut sukayu dan hitayu serta dirghajiwitam. Dalam konsep ini seorang yang disebut sehat adalah bila dirinya mencapai sukhayu yaitu bahagia secara fisik dan hitayu yaitu bahagia secara sosial dialami selama umur hidupnya (dirghajiwitam). Bila seorang hanya berumur panjang tetapi menderita sakit-sakitan, maka orang tersebut belum dikatakan sehat menurut ayurweda. Begitu pula bila orang mampu melakukan pekerjaan sehari-hari karena badan kasarnya sehat tetapi tidak mempunyai kontak sosial denganmasyarakat lingkungannya dengan baik maka orang tersebut juga belum dikatakan sehat menurut ayurweda. Prinsipnya adalah bahwa sehat menurut ayurweda pada konsep ini adalah jika keadaan sehat dicapai dalam bentuk fisik dan mempunyai kontak sosial yang baik di masyarakat dialami selama umur hidupnya, barulah orang itu disebut sehat. Dengan demikian pemahaman terhadap badan fisik ini menjadi sangat penting. Fisik manusia dalam ayurweda disebut sarira. Dan sarira ini mencakup dua hal yaitu Sthula Sarira yaitu badan kasar, dan suksma sarira yaitu badan halus yang tidak kasat mata. Demikian pula pemahaman terhadap kontak sosial merupakan bagian dari pemahaman pribadi oleh orang bersangkutan apakah telah mengalami kebahagian dalam pikrannya sendiri ataukah belum. Seorang akan bisa mengadakan kontak sosial yang baik apabila mereka mengalami bahagia dalam dirinya sendiri terlebih dahulu sebelum berhadapan dengan lingkungannya.

2.3.3 "Swasthyasya Swasthya Raksanam, Vyadhi/Duhka Parimoksanam”. Dari konsep ini maka seorang akan mencapai sehat menurut ayurweda jika seorang mampu mempertahankan kondisi sehatnya serta berhasil menanggulangi segala macampenyakitnya menjadi sembuh kembali. Diingatkan kepada semua orang bahwa kesehatan itu sangat penting dan bahkan mahal harganya karena memelihara kesehatan adalah tugas berat seorang dalam hidupnya. Jika seorang sudah sedang dalam kondisi sehat walafiat, dalam ayurweda diwajibkan untuk rakshanam (memelihara) dengan baik agar selalu dalam kesadaan sehat seperti halnya kendaraan pada saat masih baik, bisa digunakan sehari-hari, perlu dilakukan pemeliharaan (sevice) rutin untuk memelihara daya tahannya. Namun jika tubuh dalam keadaan duhka atau menderita (sakit) maka seorang wajib menanggulanginya/mengobatinya sampai sembuh. Selanjutnya jika sudah sembuh, kembali wajib mempertahankannya agar setelah sembuh senantiasa sehat dan walafiat.

Konsep sehat menurut Ayurweda ini identik dengan konsep sehat menurut WHO yang pada tahun 1947 diproklamirkan sebagai berikut : "Health is a state of complete physical, mental, spitritual and social wellbeing and not merely the absence of desease or infirmity (sehat adalah kondisi yang lengkap meliputi sehat fisik, mental, sosial, spiritual serta tidak hanya terbebas dari penyakit dan kelemahan saja). Jika disimak dari kedua konsep ini (Ayurweda dan WHO) maka akan ada persamaan pemahaman yaitu bahwa sehat adalah kondisi optimal dari faktor fisik (sthulasarira), mental, spiritual (suksmasarira) dan sosial (hitayu).

\subsection{Tri Upastambha}

Terdiri dari kata Tri yang artinya tiga dan Upastambha artinya pilar penguat .Sehingga TriUpastambha artinya adalah 3 (tiga) pilar 
penguat untuk mempertahankan kesehatan. Dalam praktek sehari-hari kalau seorang datang berobat ke dokter kemudian dokter memberikan obat rawat jalan, atau setelah pulang dari perawatan rumah sakit, secara umum pasien senantiasa dinasihati oleh tenaga kesehatan agar pasien menjaga makanan, memelihara waktu istirahat yang baik dan memperhatikan aktivitas jangan sampai berlebihan karena aktivitas yang berlebihan justru akan merusak kesehatan. Semua saran tersebut tentu ada dasarnya mengingat makanan, pengaturan pola tidur/istirahat dan menjaga aktivitas agar tidak berlebihan dapat membuat badan segar dan pikiran menjadi sehat. Hal ini menunjukkan bahwa pasien harus menjaga tiga hal pokok untuk terpeliharanya kesehatan.Dapat dipastikan bahwa tenaga kesehatan tersebut telah mempelajari hal-hal yang berkaitan dengan pemeliharaan kesehatan tubuh agar tidak menderita sakit lagi setelah dirawat di rumah sakit atau setelah dirawat di tempat praktek.

Penjabaran tentang TriUpastambha termuat pada beberapa pustaka ayurweda. Seperti yang tertulis dalam pustaka CarakaSamhita (dalam Ranade, 2007:13), Bab SutraSthana 11, sloka 35 yang biasa ditulis C.Su.11:35 disebutkan bahwa TriUpastambha terdiri dari : Ahara; Nidra dan Brahmacarya.Ahara hubungannya dengan makanan, Nidra hubungannya dengan pola tidur termasuk didalamnya adalah pengaturan saat istirahat.Sedangkan brahmacarya hubungannya dengan pengendalian energi seksual dalam tubuh.Ahara merupakan faktor penting dalam ayurweda karena intake makanan yang baik dari segi kwalitas akan membuat tubuh menjadi sehat, membuat jaringan plasma, komponen darah, otot, lemak, tulang, sumsum tulang dan hormon (dalam ayurweda disebut sapta dhatu) menjadi kuat.

\subsubsection{A h a r a (makanan/food)}

Ahara adalah segala sesuatu yang dimakan dan diminum masuk ke dalam saluran pencernaan dapat menyehatkan badan.Sehingga minuman tergolong juga ke dalam kelompok makanan.Kriteria makanan yang sehat meliputi rasa, bau, warna yang menyehatkan. Memakan makanan sebaiknya adalah yang segar, artinya segalanya dimakan dalam kondisi segar. Seperti buah yang sudah matang baru dipetik sebaiknya langsung dimakan. Dalam ayurweda, makanan yang sehat dibutuhkan tubuh bukan hanya untuk kepentingan jasmaniah saja namun makanan potensial akan mempengaruhi kondisi mental dan dapat memperkuat kondisi psikologis seorang (Ranade, 2007:86). Memakan makanan dan meminum minuman segar dan alamiah membuat tubuh menjadi kuat, saluran pencernaan menjadi terawat dengan baik dan pada akhirnya mendorong kekuatan energi prana. Berdasarkan sifat-sifat makanan diantaranya adalah rasa, substansinya, efeknya terhadap kesehatan, oleh maharshiCaraka (dalam Ranade 2007) makanan dikelompokkan menjadi 12 kelompok (varga) yaitu :

1) Shukadhanyavarga, yaitu kelompok bijibijian seperti beras, gandum. Kelompok ini diperlukan untuk membuat tridosha senantiasa dalam keadaan seimbang. Dari segi potensinya, masing-masing spesies dari golonganini memiliki sifat yang lebih mengkhusus. Ada yang khusus meningkatkan vata, pitta dan kapha atau memelihara ketiga tridosha sekaligus contohnya adalah beras hitam (shastika). Jagung termasuk dalam golongan ini yang berpotensi meningkatkan vata dan menurunkan kapha, pita. Seorang yang banyak makan jagung berpotensi banyak gas yang dihasilkan dari pencernaannya.

2) Shamidhanyavarga, di sini termasuk adalah kacang-kacangan. Kebanyakan dari kacangkacangan ini berpotensi meningkatkan vata serta berefek menyebabkan sembelit. Kacang-kacangan berwarna hitam dikatakan dapat meningkatkan kapha, merangsang nafsu seksual, membentuk feses yang baik dan meningkatkan sekresi semen dalam sperma. Kacang hijau (mudga) mengandung banyak protein nabati, baik untuk memelihara liver, kulit dan baik pencernaan pada musim panas.

3) Mamsavarga, di sini adalah kelompok daging, telor. Merupakan makanan yang dibutuhkan untuk pertumbuhan jaringan otot dengan cepat dalam tubuh. Meningkatkan kapha dan pita, mengurangi vata. Diakui bahwa golongan mamsa ini baik bagi penderita anemia, untuk mereka yang mengalami kelainan saraf dan otot, miningkatkan asam amino essensial, namun mamsavarga ini juga dikatan sebagai sebagai makanan tamasika. Bagi yang memakannya akan mempunya karma buruk dalam kehidupannya karena darinya akan ada upaya pembunuhan banyak binatang yang tak berdosa. 
4) Shakavarga, adalah kelompok sayursayuran. Sudah tentu disini termasuk, akar, batang, daun, bunga dan buahnya untuk sayuran. Ayurweda sangat menganjurkan makanan jenis ini karena aman dalam pencernaan. Memelihara sistem pencernaan menjadi sangat bagus, enzim-enzim diproduksi dengan teratur sehingga seorang akan memiliki sistem pencernaan yang prima. Meningkatkan pitta, agni dalam sistem pencernaan, dan mengeleminasi toksin. Jamur termasuk dalam golongan ini yang berefak pada diuritika yaitu dapat emproduksi urine untuk menurunkan sembab pada tubuh.

5) Phalavarga, adalah buah-buahan. Disini berbeda dengan buah-buahan yang tergolong shakavarga. Kebanyakan makananan golongan buah ini bersifat satwika. Buah anggur dikatakan bersifat diuritik maupun laxatif (mempermudah buang feses). Mangga (amra) dan pepaya baik untuk yang gemar makan daging guna mengurangi efek daging dalam tubuh. Jeruk, jeruk nipis baik untuk pencernaan dan melindungi ginjal karena banyak mengandung vit. C. Pisang baik untuk memelihara pencernaan mengurangi keluhan wasir, diare dan desentri.

6) Haritavarga, adalah makanan yang diperoleh dari umbi-umbian seperti jahe, wortel. Jahe (shunthi) dapat meningkatkan nafsu makan, menurunkan aktivitas pencernaan yang berlebihan, dan mengurangi keluhan mual muntah. Menurunkan ketiga tri dosha (vata, pita, kapha). Bawang termasuk dalam golongan ini. Di sini bawang dapat sebagai antiseptikexpectoran dan antibiotika.

7) Madyavarga, adalah makanan/minuman yang mengandung alkohol. Dikatakan golongan ini adalah golongan rajasikaahara yaitu dapat membangkitkan energi lebih banyak. 30-40 cc minum alkohol dalam ayurweda dikatakan dapat memelihara energi dan melindungi pencernaan. Dapat memperbaiki kondisi liver dan kerusakan jaringan otak. Meminum sampai $50 \mathrm{cc}$ anggur beralkohol dikatakan dapat melindungi jantung dari penggumpalan flek atheroschlerotik dan membuat otot jantung lebih kuat. Beberapa minuman keras seperti wiski, brandy dll, tidak baik untuk liver, saraf, otak dan darah karena dapat menurunkan kerja jaringannya. Minuman bir merupakan diuretik, namun meminum dalam jumlah berlebihan membuat tubuh menjadi sembab dan mudah menderita obesitas.

8) Jalavarga, adalah air. Disini air dikelompokkan menjadi dua yaitu air sungai dan air laut (ganggajala dan samudrajala). Air hujan termasuk dalam ganggajala. Sesungguhnya air hujan murni tanpa polusi seperti sekarang ini, air hujan direkomendasi oleh ayurweda untuk diminum karena sifatnya yang sejuk dan memperbaiki pencernaan.

9) Gorasavarga, yaitu minuman susu, santan,meningkatkanpitta, memperbaiki pencernaan, memudahkan membuang feses, memperbaiki plasma darah dan organ reproduktif seperti ovarium, testis. Kebanyakan golongan ini merupakan makanan satwika, memperbaiki otak dan kondisi psikologis. Susu yang segar dicampur ghee merupakan makanan yang sangat digemari karena bisa sebagai tonikum dan memperbaiki proses peremajaan sel. Termasuk dalam golongan ini adalah susu sapi, kambing, keju, mentega, yogurt.

10) Ikshuvarga, adalah golongan pemanis/gula. Misalnya gula tebu, dapat meningkatkan kapha, merangsang nafsu seksual, laxative. Madu termasuk dalam golongan ini. Madu baik untuk memelihara semua tridosha. Madu menurunkan kapha. Merupakan makanan yang penuh gizi, bisa dimakan dalam segala musim.

11) Kritannavarga, adalah campuran makanan olahan seperti, makanan dari hasil fermentasi, goreng-gorengan, panggang, rebus, masakan. Nasi kukus, baik untuk meningkatkan kapha. Makanan yang diolah dijaga untuk kesehatan agar tidak susah dicerna oleh slauran pencernaan akan baik untuk kesehatan. Hindari dari penyimpanan yang lama dan pemakaian bahan-bahan pengawet yang mengandung toxin.

12) Aharayogin, yaitu makanan tambahan penyempurna rasa. Seperti minyakminyakan, garam-garaman, merica, serbuk jahe dll. Tilataila (sesameoil) baik untuk mengurangi vata dan kapha. Sangat baik untuk kesehatan kulit, menghilangkan ketegangan otot dan saraf shingga sering 
digunakan dalam masase. Juga berfungsi sebagai laxative dan peremajaan sel. Sedangkan minyak kelapa baik untuk pitta, memelihara usus, meningkatkan sukradhatu/potensiasi kekebalan tubuh. Minyak bunga matahari baik untuk melindungi saluran pernafasan pada kondisi seorang dalam keadaan radang saluran pernafasan.

\subsubsection{Nidra}

Di dalam ayurweda diuraikan beberapa jenis tidur yang dialami oleh seseorang. Namun tidur yang secara alami menurut ayurweda adalah tidur yang dialami dari proses mengantuk tatkala malam hari. Jenis tidur menurut ayurweda adalah :

1) Tamobhava adalah tidur akibat sifat tamas (malas) menguasai diri seorang. Mereka akan tidur pada setiap kesempatan dan dengan mudahnya mereka tertidur.

2) Shleshma-samudbhava adalah akibat meningatnya unsur kapha dalam tubuh sampai mengakibatkan adanya kebuntuan salurandari rangsangan saraf.

3) Manah-sarir-sharama-sambhava, adalah ketiduran akibat kelelahan fisik dan pikiran.

4) Vyadhyanuvartini, adalah tidur akibat adanya gangguan sakit.

5) Agantuki, yaitu ketiduran yang terjadi secara tiba-tiba tanpa sebab yang jelas. Pada kondisi ini soeorang diperkirakan mengidap kekurang harmonisan terjadi pada pusat tidur di otak.

6) Ratriavabhava-prabhava, yaitu tidur yang diperoleh secara alamiah memasuki malam hari. Tidur ini adalah normal karena seorang akan merasa kantuk di malam hari kondisi lingkungan yang sejuk dan hening akan menyebabkan faktor tamas menjadi aktif, meningkatkan rasa kantuk. Dalam satu hariterutama pada siang hari seorang telah terbangun dan melek. Budi satwanyasangat berperan sehingga seorang terangsang dan aktif aktif sementara pada malam hari, budi tamas datang mengakibatkan ada rasa kantu.

Lamanya waktu tidur menurut umur pada masa bayi seorang memerlukan waktu lebih lama untuk tidur karena sedang dalam pertumbuhan otak dan sel-sel saraf. Seorang bayi yang baru lahir akan tidur selama 3 jam terus menerus kemudian bangun untuk makan, bermain, buang kotoran,urine, setelah kemudian secara alami akan tertidur lagi. Lamanya waktu tidur yang dibutuhkan sesuai dengan umur tampak seperti pada tabel di bawah ini (Ranade, 2007 : 14) :

\begin{tabular}{|l|l|}
\hline U m u r & $\begin{array}{l}\text { Waktu tidur yang } \\
\text { dibutuhkan (Jam) }\end{array}$ \\
\hline $0-1$ bulan & $18-20$ \\
\hline $1-6$ bulan & $15-18$ \\
\hline 6 bln -1 tahun & $14-16$ \\
\hline 1 tahun -2 thn & $12-14$ \\
\hline $2-5$ tahun & $10-12$ \\
\hline $5-16$ tahun & $9-10$ \\
\hline dewasa & 8 \\
\hline Orang tua & $4-6$ \\
\hline & \\
\hline
\end{tabular}

Kemudian tidur juga dipengaruhi oleh triguna. Bagi orang yang satwika, memerlukan 4-6 jam tidur sehari, sedangkan orang yang berbudi rajas memerlukan 8 jam, tamas 10 - 12 jam.Pada saat tidur maka aktivitas saraf simpatis akan bekerja menurun sedangkan saraf parasimpatis akan meningkat. Hal ini akan mengakibatkan pada saat tidur : tekanan darah akan menurun secara perlahan, begitu pula denyut nadi. Basal Metabolism Rate (BMR) sekitar 10-20\%, ketegangan otot berangsur juga menurun, pembuluh darah pada permukaan kulit akan mengembang (dilatasi) sedangkan aktivitas gastro intestinal seperti pencernaan akan menigkat pada saat tidur tersebut. Kualitas tidur (yuktanidraguna) amat sangat dibutuhkan untuk mencapai keseimbangan tridosha. Keseimbangan tridosha merupakan dasar terjadinya kesehatan baik fisik maupun kondisi pikiran akan terjaga kesehatannya ketika kualitas tidur dapat dipelihara. Untuk memelihara kesehatan seorang yang bekerja fisik dan pikiran yang berlebihan dalam keseharian disarankan tidur (nidra) melebihi dari waktu normal tidur seperti pada tabel di atas.Tidur siang (dipasvapah) bagi seorang yang sehat tidaklah dianjurkan, namun tidur siang dapat dilakukan ketika aktivitas fisik melebihi dari normal dan sering terjaga pada malam hari. Seseorang diharapkan bisa mengatasi dirinya dari gangguangangguan tidur seperti terjaga di malam hari (ratrijagaranam), susah tidur atau insomnia (anidra) maupun kelebihan tidur (ati-nidra). Kelebihan tidur berpotensi mengakibatkan obesitas dan memicu bangkitnya penyakit kencing manis.

2.4.3.Brahmacharya 
Brahmacharya dalam ayurweda terdiri dari kata Brahma yang artinya Tuhan atau Ilmu Pengetahuan (khususnya tentang Ketuhanan/upaisad).Acarya berarti tugas-tugas.Jadi Brahmacharya merupakan aturan yang harus dilakoni selama menuntut ilmu pengetahuan Ketuhanan. Watsyayana seorang ahli ilmu seksiologi India menulis dalam bukunya 'Kamasutra' (dalam Ranade 2007: 47) mengatakan bahwa seorang anak sampai berumur 17 tahun (bahlyavastha) wajib melaksanakan brahmacharya karena usia tersebut adalah usia dimana seorang sedang dalam menuntut ilmu. Pada usia dewasa seorang yang menuntut ilmu Ketuhanan juga sama halnya dengan usia bahlyavastha perlu mengendalikan energi seksualnya untuk keberhasilannya karena menuntut ilmu pada usia dewasa dianggap kembali lahir seperti anak baru lahir. Jika energi seksual tidak diatur dengan baik, maka upaya untuk menjadi hidup sehat akanterganggu. Membiarkan nafsu seksual tidak terkontrol bisa menyebabkan kelemahan, menurunnya kekebalan tubuh (ojakshaya), mudah diserang penyakit fisik maupun mental serta mempercepat kematian (Ranade, 2007 : 47). Sukra yang merupakan bagian dari saptadhatu di dalam tubuh perlu dijaga untuk mempertahankan kesehatan. Dari sukra (elemen cairan reproduksi) ini akan menimbulkan ojas (material abstrak) yang memberikan support kepada energi tubuh, kekuatan fisik dan kekebalan terhadap penyakit (immunity). Adalah identik dengan prana (energi vital) ysng menyebabkan kekuatan fisik dan mental spiritual.Itu makanya memelihara kesehatan diawali dengan melaksanakan brahmacharya adalah suatu yang penting dalam ayurweda.

Di dalam kitab Silakrama (Puniatmaja 1976, 11) dijelaskan tentang brahmacharya sebagai berikut :

"Catur asrama ngaranya Brahmachari, Grhastha, Wanaprastha. Brahmacari ngaranya sang sedeng mangabhyasa sanghyang sastra mwang sang wruh ring tingkah sanghyang aksara. Sang mangkana kramanya sang brahmacari ngarania. Kunang sang sinangguh brahmacari ring loka, ikang tan sanggraheng wisaya stri adi, yeka brahmacari ring loka. Kunang ikang brahmacari waneh sinangguh brahmacari caranam, paraning atmapradesa.Sangksepania sang yogiswara sira brahmacari ring sastrantara ring sastrajna..."

Artinya:CaturAsrama itu terdiri dari Brahmacari, Grehasta, Wanaprastha dan Biksuka. Brahmacari adalah orang yang sedang mempelajari satra dan yang mengetahui tentang aksara.Yang demikian keadaannya disebut brahmacari.Namun yang disebut brahmacari di masyarakat adalah orang yang tidak kena wanita seperti isteri.Itu brahmacari di masyarakat.Yang disebut brahmacari selain itu adalah yang namanya brahmacaricaranam mementingkan pelajaran tentang jiwa.Kesimpulannya, seorang yogi juga adalah brahmacari dalam pelajaran sastra dan pengemban ilmu pengetahuan.

Kalau disimak dari uraian Silakrama di atas dan kaitannya dengan yang ada dalam ayurweda (dalam Ranade, 2007) maka terlihat ada kemiripannya yaitu adanya upaya mengontrol nasfu seksual atau energi seksual agar senantiasa sehat guna mampu mengikuti kewajiban pelajaran sampai berhasil. Dalam rangka menuntut ilmu baik pada usia di bawah 17 tahun maupun dalam mendalami ilmu tentang Ketuhanan / upanisad, diperlukan tubuh/badan dan mental yang sehat. Untuk memperoleh badan/tubuh dan mental yang sehat salah satunya adalah dengan mengendalikan nafsu atau energi seksual yang merupakan bagian dari TriUpasthamba.

\section{Simpulan dan Saran}

\section{a. Simpulan}

Dari pemaparan di atas, dapat diambil beberapa kesimpulan yaitu :

1) Kitab Ayurweda yang merupakan kitab Kedokteran Hindu adalah bagian dari kitab weda (upaweda) yang isinya bersumber dari kitab Atharva Weda.

2) Maharshi Caraka dan Susrutha dalam kitab ayurweda banyak memberikan tuntunan kepada umat manusia untuk bisahidup sehat dan berumur panjang sebagaimana arti ayur/ayu (sehat, berumur panjang) dan weda (pengetahuan)

3) Di dalam kitab ayurweda terkandung konsep-konsep mengenai cara hidup sehat. Hidup sehat senantiasa harus diupayakan dan bisa dipertahankan. Sehat tidah hanya fisik tetapi meliputi spiritual.

4) Dengan menyimak ajaran TriUpasthamba yang terdiri dari ahara (perhatian terhadap makanan), nidra (perhatian terhadap upaya istirahat/tidur) dan brahmacarya (perhatian upaya sehat dengan pengendalian energi seksual) kesehatan dapat dipelihara secara terus menerus dalam kondisi prima. 
5) Membina kesehatan untuk kepentingan diri sendiri dan masyarakat menurut ayurweda dapat diperoleh dengan melaksanakan konsep Tri Upastambha.

\section{b. Saran}

Dalam mempelajari hakikat ayurweda, hendaknya dipelajari secara rinci keterkaitan ajaran kitab weda dalam agama Hindu kendatipun isinya sangat luas dan memerlukan pemahaman khusus.

1. Merupakan tugas setiap generasi untuk meneruskan kebiasaan-kebiasaan para maharshi mengadakan penelitian berkaitan dengan ilmu pengobatan agar penulisan-penulisan kitab ayurweda senantiasa sesuai dengan perkembangan jaman dan perkembangan penyakit.

2. Karena pemahaman kesehatan dalam ayurweda meliputi spiritual, maka hendaknya belajar kesehatan tidak cukup mempelajari yang kasat mata saja, perlu juga yang bersifat supra natural.

3. Dengan dasar ilmu Tri Upastambha, hendaknya setiap pelaku kesehatan dapat memberikan pendidikan kepada pasien agar dalam dirinya tumbuh rasa kewajiban memelihara kesehatan mulai dari sendiri sendiri karena masalah kesehatan adalah masalah bersama.

4. Kepada segenap umat Hindu agar menjadi pelopor dan panutan dalam mengembangkan ayurweda yang di dalamnya terkandung ajaran kesehatan terpaut dalam ajaran agama.

\section{Daftar Pustaka}

Dash, VB dan Suharsini R. 2006.Ayurweda Ilmu Pengobatan Tradisional India.Penterjemah : Ir. I Gede Ngurah Ambara.Surabaya : Paramitha.

Hanum Marimbi, 2009. Sosiologi dan Antropologi Kesehatan.Jogyakarta : Nuha Medika

Mantik, Agus. 2000. "Ayurweda" terjemahan dari Ayurveda oleh Dr. Vasant Lad \& Robert E. Sovaboda. Surabaya : Paramitha.

Mahadevan, 2012. Ayurveda for beginners. Chennai India : Chuvadi.

Manuaba, IB. 2011. Ayurweda Ilmu Kedokteran Hindu.Denpasar : $\quad$ Yayasan Dharmopadesa.

Mehta, Anil, K. 2010.Ayurvedic Physiotherapy \& Yoga. Neh Delhi : AK Lithographers.
Nala, Ngurah. 2001. Ayurweda Ilmu Kedokteran Hindu I dan II.Denpasar : Upada Sastra Keemeneg Agama RI 2007.Kosmologi Hindu. Surabaya : Paramita

Ngurah, I Gst. Md, dan Kawan-kawan Tim Penyusun. 2012. Dasar-Dasar Agama Hindu : Jakarta: Dirjen Bimas Agama HinduParisada Hindu Dharma Pusat.

Puniatmaja, 1976.Silakrama.Jakarta :Bimas Hindu Buddha Kemeneg Agama RI

Ranade, Subhash. 2007. A Textbook Of Svasthavritta. New Delhi : AK Lithographers.

Sharma. 2012. "Advance Consep of Ayurveda". Materi Kuliah Umum, disampaikan pada kuliah umum Ayurweda 18 Desember 2012 di kampus UNHI Denpasar. 